\title{
Holistic Linguistics: Anthropocentric Foundations and the Functional-Cognitive Paradigm
}

\section{Elena Tyurkan (Belichenko)}

This paper dwells on some aspects of language, grammar in particular, through the prism of the functional-cognitive approach. It covers such issues as language and mind, the embodiment of language, the peculiarities of language acquisition, and the metaphoric nature of the human mind. The functional-cognitive approach is regarded as part of a holistic anthropocentric paradigm where language is conceived of as a natural biological phenomenon connected with the adaptive functions of a human being as a holistic living organism. A new paradigm gives rise to new epistemologies and generates new forms of scientific collaboration. Thus, neurosciences, quantum physics, and biology become involved in processing language data, influencing the direction and goals of linguistic research. As suggested by the author of this paper, changes in language can be viewed with regard to quantum effects observed in the macroworld, or an autopoietic reconstruction of the language system. Dwelling on the ideas of cognitive typology, the paper also makes an attempt to elucidate some reasons for the appearance of new structural features in language which influence the reconstruction of its grammatical interface in the first place. Such processes are viewed as the reflection of global shifts in the linguistic world image of language bearers under the influence of the outer world/extralinguistic factors, and as connected with encoding by language of the changes in socio-discursive parameters of the intercourse. Finally, some perspectives of grammar analysis are outlined.

\section{Keywords}

Functional-cognitive approach; holistic interpretation of language phenomena; alternative research paradigms; universal typological principles; grammar as a language generator.

\section{Introduction}

Like any other science, linguistics has passed through several stages in its 
development: the stage of collecting data, the stage of data classification, and the stage of data interpretation. According to Kybrik, linguistics of the 2oth century, which can be described as "HOW-Linguistics" (how language is organised), is changing into "WHY/WHAT FOR Linguistics" with the prevalence of the explanatory paradigm (Kibrik 91).

Actually, it was already in 196os that Greenberg, Jenkins and Osgood laid special emphasis on the necessity of an interdisciplinary approach to linguistic research:

(...) since language is at once both an aspect of individual behaviour and an aspect of human culture, its universals provide the major point of contact with underlying psychological principles (psycholinguistics) and the major source of implications for human culture in general (ethnolinguistics). (Greenberg et al. 25)

Hence, as has been suggested among others by Kubryakova, linguistics of the 2oth and the beginning of $21^{\text {st }}$ centuries can be regarded as linguistics of expansion, for it has established close links with other sciences, such as anthropology, neurosciences, cybernetics, etc.; as linguistics of anthropocentrism and cognitivism owing to the fact that the main subject of its research is the human as a language bearer; as linguistics of functionalism, since modern linguistics studies all the diversity of functions performed by language trying to explain their varying multiplicity (Kubryakova 144-238).

This paper is going to examine several areas of multiaspectual growth of linguistics as part of an anthropocentric scientific paradigm. More specifically, rather than various social-discursive dimensions, it will explore some current functional-cognitive approaches to linguistic analysis, and will strive to outline possibilities for its further growth, chiefly by means of applying data of other sciences for the interpretation of language peculiarities, pre-eminently grammar.

\section{Cognitive Linguistics through the prism of Functionalism: a new vision of the old or a crisis of goals?}

The first attempts to apply an integral multi-disciplinary analysis to language data were made in the 1960 . In fact, one of the most prominent events of this 
period was the famous Dobbs Ferry Conference of 1961 in New York. However, the "cognitive revolution" took place only in the 1980 os and resulted in a shift of the focus in mainstream research for all the humanities, linguistics included, to the aspects of thinking and meaning, attaching them special significance in structuring and modifying the medium.

Aiming at newly established goals, scholars working in the domains of cognitive linguistics, psycholinguistics and biopsychology, cognitive typology, and cognitive semantics (McCawley, Lakoff, Miller, Jonson-Laird, Croft, Turner, and others), specified such anchor domains for modern linguistic research as communication, interaction, culture, habitus, cybernetics, and cognition. Thus, the perspectives of modern linguistics arose as a broadly interpreted explanatory paradigm converging cognitivism and functionalism, where functionalism is viewed as an immediate explanatory constituent (Nikolaeva; Kubryakova 149). Meanwhile, one of the main postulates of functional linguistics - what functions an element performs due to its nature and accommodation faculty to the tasks required by the environment and the situation - is harmoniously combined with major goals of the cognitive approach which treats language as an instrument of cognition and its representation.

As Thompson notes, the general characteristic of all functional research is the idea of basic structural language parameters as originating from the "ecological context" in which every language functions (Thompson 93). Thus, in functional linguistics, a "peculiar language behaviour" can be explained through several principles. The first one is described as iconicity or a nonrandom correlation in the dichotomy "form-function". It presupposes the conceived similarity, or analogy between the form of an element and its meaning. The next principle concerns economy, or the choice of shorter and more 'active' forms in equal conditions of functioning. The principle of discursive motivations of grammar implies that the speaker's choice of a grammar construction is predetermined by everyday discourse. Finally, a diachronic explanation for any language model establishes a significance of earlier stages in the language development for the analysis of its synchronic stage (cf.: Kibrik, Plungyan 28o-282).

What functional linguistics also strives to reveal is the causes of language diversity, chiefly considering the correlation "form-function". The latest research in this domain focuses on the following evidence when approaching this issue: the first concerns the existence of equally probabilistic motivations, such as iconism and economy, rivalling with each other within the language 
system on the level of expression. The second establishes the primordial dependence of grammar on such domains of human activity as cognitivism and pragmatism. Hence, grammar is viewed as being generated in the course of the progression of competing discursive motivations reflecting the cognitive-pragmatic intentions of the speaker. The third evidence springs from the assumption of the necessity to analyze cognitive principles, pragmatic principles, and the principles of "routinisation", involved into the process of grammar generation, within the framework of an integral explanatory paradigm that is a characteristic feature of grammar foundations (cf.: Kibrik, Plungyan 276-277).

Evidently, functional and cognitive approaches have so many crosspoints that cognitive linguistics is held to be part of functionalism. As Kybrik notes, "the cognitive approach is one of the methods to interpret language phenomena". The matter is that "today's cognitivism could be better described as a conglomerate of related but coexisting branches" (Kybrik 324, as translated by Tyurkan), though a progressive character of the cognitive approach is undeniable. As Fauconnier claims, a striking success of the cognitive paradigm is explained by the fact that

Cognitive Linguistics goes beyond the visible structure of language and investigates the considerably more complex backstage operations of cognition that create grammar, conceptualisation, discourse, and thought itself. The theoretical insights of Cognitive Linguistics are based on extensive empirical observation in multiple contexts, and on experimental work in psychology and neuroscience, and though the main focus of Cognitive Linguistics is not new (language as a means of meaning evolution and transfer), its methods are new (Fauconnier).

Tracing the beginnings of the cognitive approach in linguistics, it becomes obvious that cognitive linguistics which emerged in the 1980s in the USA has much in common with Chomsky's generative linguistics. In early cognitive research, language is defined as a sign system whose main functions are categorisation, storing, extraction and processing of information. Therefore, meaning is understood as information (Fodor 119). As Kravchenko aptly states, cognitive linguistics regards language as a generative system, i.e., mental representation of a speaker's grammar which structures mental processes. This way, it continues developing Chomsky's idea of major goals for linguistics and lays special emphasis on the study of competence as the main cognitive 
human faculty that is formed and represented through language means, speech production, and speech perception (Kravchenko, Kognitionaya Linguistika 124).

However, a shared object of studies does not guarantee the unity of tasks and goals, especially if we admit the fact that an "ideal project" for linguistics has not been established yet (cf.: Frumkina et al; Kravchenko, Toward a Biocognitive Philosophy; Sign). Therefore, it is essentially important to find adequate ways and modes of integrating all knowledge about language accumulated by different scientific schools. Consequently, one of the questions that naturally arises is "What should linguistics study and what for?", where "WHAT?" means that we should treat language as an empiric phenomenon because until and unless we do so, the question "WHAT FOR?" remains unanswered. Moreover, despite all promising development prospects in the field of linguistics provided by the new line of investigation, the status of the main language function communicative, cognitive, or both - remains another crucial issue.

Nowadays it is possible to assume that in the development of modern linguistics, a turning point is inevitably to come, and this point is part of a new ideology of physicalism and radicalism, which attaches utmost significance to two issues of a modern research paradigm - how to investigate, and the relations between mind and body (cf.: Devitt \& Sterelny; Givón, On the Intellectual; The Visual; Lakoff, Categories; Linguistics; Lakoff \& Johnson; Langaker; Kravchenko, Kognitivnaya linguistika; Toward a Bio-cognitive; Sign; Kognitionaya Lingvistika Segodnya; Zlatev, A Hierarchy). The new ideology has evolved from ancient classical paradigms and poses a question about the embodiment of our mind. The main idea, purported by it, states that any analysis separating language and corporal stimuli can hardly be regarded accomplished, as these two constituents determine and predetermine each other. Moreover, as Lakoff claims, further progress for research in the linguistic field is impossible without the integration of linguistics and the neuron theory, neurophysiology and neuropsychology included.

The main principles of the new ideology can be outlined as follows:

- the mind is inherently embodied;

- thought is mostly unconscious;

- abstract concepts are largely metaphorical;

- reason is not disembodied, as the tradition has largely held, but arises from the nature of our brains, bodies, and bodily experience;

- reason is evolutionary;

- reason is not completely conscious, but mostly unconscious; 


\section{ELENA TYURKAN}

- reason is not purely literal, but largely metaphorical and imaginative;

- reason is not dispassionate, but emotionally engaged.

Thus, to understand reason, we must understand the details of our visual system, our motor system, and the general mechanisms of neural binding (cf.: Lakoff \& Johnson 77-78).

Hence, the processes of conceptualisation and categorisation appear to be interpreted on relatively new foundations. Similarly, an intriguing conception of the Idealized Cognitive Model by Lakoff and Johnson acquires a new, more elaborate application: when we reconstruct concepts kept in our linguistic consciousness as the reflection of the world image and realise how a concept arises in our mind, we use the Idealized Cognitive Model which shows the 'paths' from an extralinguistic object or phenomenon to the record of its presentation in the mind. Hence, it is maintained that one and the same chain of metaphors 'accompanies' a concept in its presentation, and serves as its generator and anchor in our mind.

Combining evidence from the latest research, a generalised presentation of the Idealised Cognitive Model is given a new interpretation with a number of differences in concept actualisation, i.e., encoding: metaphorics does not always provide a unified holistic model of an object (phenomenon), or a unified holistic concept - moreover, it leads to 'visualising' only some aspects or sides of it. As Zaliznyak notes, "our attempts to construct a holistic image from various metaphoric combinations are very much akin to the situation when several blind people from a famous Indian fairy tale were trying to describe an elephant having touched only one part of its body" (Zaliznyak 61, as translated by Elena Tyurkan). Rakhilina claims that treating concept as a holistic structure makes us realise that every construction "has its own concept presentation which differs from other presentations of the same extralinguistic object or phenomenon. For example, the concept of a container is represented differently through the prism of the genitive construction ( $a$ glass of water), locative presentation (water in the glass), size parameter ( $a$ tumbler), comitative construction (a glass with water)" (Rakhilina, as translated by Elena Tyurkan).

Therefore, all metaphoric "reconstructions" should be analyzed on diachronic principles, as metaphors reflect not only an existing situation at present, but transfer "traces" connected with earlier stages of the world image. In fact, similar ideas are developed in the conceptions by Givón and Plungyan with respect to grammar structure, to be discussed further. This 
assumption is rather essential because it may help us establish the validity of some characteristics of the past in their influence on the image of the contemporary world. If we do not take it into consideration, "we risk to get a mosaic image constructed not only of various details, but of different planes, or, to continue the witty metaphor by Zaliznyak, the blind people may come across not an elephant, but other animals" (Rakhilina, as translated by Elena Tyurkan).

\section{Sign, meaning, concept: traditional and holistic interpretation}

Developing the ideas of the previous part, it is necessary to dwell on the issue of the relation between three fundamental notions of linguistics, namely sign, meaning and concept. The fundamental principle of binarity lying in the scenario of rational behaviour comes from the assumption that human thinking and processes of decision making always follow the scheme "either A or B" and comply with the laws of logic. Such an approach is used as an epistemic foundation of traditional (analytical) Western Philosophy with its ontological separation of mind and body. As for methodological aspects, the absurdity of such separation has been recognised only recently: the idea of different ontologies for mind and body leads us to perceiving the mind as something that exists beyond the body. Thus, for linguistic analysis this assumption means that language with its symbols exists independently of the body. In a similar way, in semiotics the concept "SIGN" is defined as a binary structure combining ontologically different components: if the body of the language sign is created to serve as a signifier, we have to conclude logically that meanings exist before signs emerge. Therefore, if we accept this assumption, we face the problem of "defining the meaning as a nonphysical entity that exists before it has cohered into a whole with some physical substance (a linguistic sign included) due to which we realize the existence of meanings at all" (Kravchenko, Kognitivnyje Gorizonty 155, as translated by Elena Tyurkan).

The matter is that the mind develops (arises) simultaneously with the body in the process of its functional interaction with the environment. Consequently, meanings are continually constructed during contacts between the organism and physical constituents that form this environment. Yet, we should not forget that from an epistemological point of view signs in general, and linguistic 


\section{ELENA TYURKAN}

signs in particular, do not differ from other physical entities and phenomena that are present in the primordial environment of the human organism. These entities may or may not become signs. It depends on the significance ascribed to them by the organism, and this significance is more individual than social in nature. As Kravchenko claims, any significance can be socialised to a considerable degree, as a result of human contacts with various types of entities and phenomena in the sphere of the shared perceptual and experience domains, but its individual "trace" can hardly be lost completely (Kravchenko, Kognitionyje Gorizonty 156). This makes it possible to surmise that neither the multitude of all possible signs, nor all the meanings ascribed to them, can be exactly and full-fledgedly defined, unless the most important factor - the human as a bearer of perception and experience - stays off-stage. Moreover, meanings of a sign are empiric in nature and emerge as a result of various contacts of the human organism with the environment. When the human comes into contact with the environment, a chain of receptors, evoking a cluster related to one or another of visual, kinesthetic, tactile, olfactory reactions accompanied by a certain acoustic word image, is activated. Therefore, the word can be called a universal channel to all the diversity of human feelings, emotions and perception at the moment of the human's interaction with any object or phenomenon of the environment.

A similar interpretation of meaning is represented by Zlatev who calls the meaning a "semiotic mediator", or a relationship between an individual and its environment, defined by the value, which particular aspects (falling into categories) hold for the individual. Other characteristics of meaning are based on:

- the value of physical aspects (categories), perceived via innate value systems and initially based on their role for the preservation of the life of the individual (and its kin);

- the value of social aspects (categories), as well as physical ones, based on their role in conventional meaning-value systems that need to be acquired by the individual before they can become meaningful;

- both innate and acquired meaning-value systems served as control systems by directing and evaluating the individual's behavior;

- value, and consequently meaning, as intimately connected to emotion and feeling.

To summarize, any system capable of meaning requires: (1) a self organizing 
body with an intrinsic value system (embodiment), (2) interaction with an environment, which for all but the simplest creatures is social as well as physical (situatedness) and, if its meaning system is not to be fixed in advance, (3) cumulative, step-wise development (epigenesis) (Zlatev, A Hierarchy).

A bio-cognitive functional approach does not interpret concept as a language phenomenon in the traditional sense. The identity between concept and notion is eliminated automatically as "notion" is referred to language, but "concept" should be regarded as an elementary unit responsible for the accumulation of human experience, its further implementation, and storage. In other words, while notion can be explicated with the help of language means, concept shows a "path" to an empiric field, i.e., some extralinguistic phenomenon. It is represented in language indirectly for it is already widely acknowledged that linguistic meaning represents concept only partially (cf.: Kravchenko, Sign; Kubryakova). Hence, meaning is recognised as not something external towards the human, but as a kind of mediator between the human organism and the environment, a form of "semiotic mediation" (Larina). Due to such interpretation, as Dirven and Verspoor conclude, "man as a conceptualizer and the world s/he experiences are given a new explication" (Dirven, Verspoor 14).

As mentioned above, one of the most controversial tasks for modern cognitive science is to identify (at least, in a general way) typical "paths" of conceptualisation, resulting from the ability of the human mind to reflect extralinguistic reality. This task appears to be rather difficult because of a high degree of subjectivity that must evidently be involved in such descriptions. Thus, to get some admissible conclusions, more or less suitable for data processing and their further verification, a researcher will have to deal with the perennial problem of the delimitation between the linguistic and the extralinguistic. Moreover, it must be accepted as inevitable that subjectivity will always be part of the research paradigm just because nowadays, in the overwhelming majority of situations, the analysis of the way cognition occurs is made possible only through language.

\section{Alternative research paradigms in Language Studies}

\subsection{Controversial issues of Biolinguistics}

By shifting the focus of its research to a comprehensive scheme that embraces even natural sciences, linguistics seeks to combine the study of biology and 


\section{ELENA TYURKAN}

evolution of language to yield a framework by which the fundamentals of the faculty of language can be understood. Accordingly, a holistic bio-cognitive approach is considered to treat language as a natural biological phenomenon, representing a unique characteristic of the homo sapiens species. The latest research of biological matters in language and the problem of language origin and evolution is quite extensive and versatile (cf.: Bikerton; Ikegami \& Zlatev; Jenkins; Pinker, Tomasello; Zlatev, Mimesis; inter alia), but all investigation focuses on some core issues connected with a holistic interpretation of language phenomena.

The first and foremost one is what language actually is - something that has been imposed on us, or the product of evolutionary development? Therefore, in order to answer the question "What constitutes the knowledge of language?" it is first necessary to say what is meant by "language" when it is treated on the biolinguistic foundations. If we abstract away from the performance system, the brain/mind can be regarded as a set of interacting modules which include the language faculty. Thus, it becomes possible to identify a cognitive system in the language faculty when language development ought to be called "language growth" because language is akin to any other body organ (cf.: Chomsky, Language and Politics 407). Besides this, most neurologists would assume that the circuits responsible for language are mainly cortical. From this it follows that we are hardly born knowing the details of our human tongue. All in all, "the five fundamental questions of Biolinguistics" (Jenkins 57) can be interpreted as the principles of Generative Grammar, and embrace the issues of understanding what knowledge of language is, how that knowledge is acquired, put to use, implemented in the brain, and how it emerged in the species (cf.: Chomsky, Language and Problems 158).

One of the basic propositions in biolinguistics is the idea that all languages originated from the same initial stage, or core. This is underpinned by evidence from studies of language acquisition and perception, cases of aphasia, sign language, etc. Abstracting away from gross pathology as well as individualisation, the theory of the initial state is represented by the "Principles and Parameters model" of Universal Grammar:

Language acquisition can be seen as the transition from the state of the mind at birth, the initial cognitive state, to the stable state that corresponds to the native knowledge of a natural language. ... the initial cognitive state, far from being the tabula rasa of empiricist models, is already a richly structured system. The theory of the initial cognitive state is called 
Universal Grammar; the theory of a particular stable state is a particular grammar. Acquiring the tacit knowledge of French, Italian, Chinese, etc., is then made possible by the component of the mind-brain that is explicitly modeled by Universal Grammar, in interaction with a specific course of linguistic experience. (Chomsky, New 8)

The processes of language acquisition can also be identified by watching children, in whom the cognitive system passes through a series of intermediate states.

An interesting example, illustrating Chomsky's idea of a universal core for every natural language, can be found in phonetic studies: adult Japanese speakers do not recognise the distinction between the sounds " $r$ " and "l", but Japanese infants make such distinctions, though only to a certain age. Similar illustrations are provided by syntax also: English speakers make syntactic distinctions between main verbs (drink, walk) and modal verbs (can, will) as well as auxiliaries $($ have, be). But those syntactic distinctions are not found in the speech of adult Swedish speakers, though Swedish children make them to a certain stage of language learning (cf.: Jenkins 26-27).

As Chomsky claims, the most controversial issues in linguistic research are connected with the study of syntax (in the present author's considerations grammar in general). In fact, in this case we deal with abstract properties of the language faculty, and not directly with brain circuits (Chomsky, Linguistics 35). Evidently, the processes of syntax acquisition are connected with the issue of language evolution. Thus, supposing that the language faculty represents only one component of the brain, we can infer that the human brain is not a homogeneous organ, consisting of areas specialised for different purposes, such as vision, the number faculty, the language faculty, etc. Actually, the processes of thinking, cognition, and perception are not connected with words directly, for even feelings and emotions can be expressed without words. Accordingly, we can assume that different subsystems of the language faculty (syntax, morphology, phonology, lexis) are connected with various parts of the human brain. When the brain is injured, or when it suffers from a disease or genetic disorder, one can observe how its submodules are selectively impaired. For example, this arises when a person cannot speak but can comprehend the speech of others, or when a person cannot build up a grammatically relevant structure, though s/he keeps the ability to read and comprehend an outer text (cf.: Jenkins 58-59). Other interesting cases which deserve being studied more closely are connected with demonstrating an extraordinary power of the 


\section{ELENA TYURKAN}

language faculty - when a damaged brain starts functioning in an absolutely amazing way.

Willy Melnikov, a famous Russian interpreter-polyglot (who is said to speak 104 languages), was badly injured during the war in Afghanistan. After the accident, he has acquired the ability to learn a language in a very short period of time. However, it would be important to mention that he had worked as an interpreter and translator before the injury and got an excellent education. His abilities have been closely studied by neurophysiologists, but the explanation to his unusual gift has not yet been found. As for his view of the abilities he possesses, Willy says that first, he "tunes" in the language, feels it as a gestalt structure, and only then starts putting sounds into words, and words into sentences. But he notes that it is important for him to listen to the sounds of the language he is going to learn - either a recording or natural speech. Despite the fact that the competence of most languages Melnikov possesses is criticised when it is compared with the level of a well-educated native speaker, his unusual gift is too obvious to be denied (cf.: Fedin).

Melnikov mentions one more phenomenon that verges on the esoteric domain, namely - channeling. It is held to help him speak and even write verses in numerous languages. Channeling is the ability to connect to the universe (the universe reason, or consciousness) for some essential information. The idea of channeling is not new and correlates with the theory of noosphere by Vernadsky, Le Roy, and Teilhard de Chardin. In some ways, it overlaps with the theories of quantum physics mentioned below. However, without accepting the 'esoteric path', language competence may be understood as collective universal knowledge which can be acquired not only genetically, but through some information channels that are unlikely to be described quite satisfactorily at present. One of the neurophysiological hypotheses explains polyglots' abilities by the size of the alba (or Heschl's gyrus), a part of the brain responsible for language acquisition: the bigger the alba area in the brain structure, the easier we learn languages. Apparently, further experiments could break new ground in this sphere (cf.: Golestiani et al.).

Concerning the perspectives of future research in the field of Universal Grammar, Chomsky notes that "many of the questions that inspired the modern scientific revolution are not even on the agenda" (Chomsky, New 58). That may impel scholars to search for and open new facets of Chomsky's conception.

Another indisputable authority in the field of biolinguistics is Givón. In his view of language as a biolinguistic phenomenon (Givón, Bio-Linguistics), 
he criticises Chomsky primarily for the lack of diachronic foundations and "an obvious disregard of communicative principia":

Chomsky had managed, rather explicitly, to build so many apparent contradictions into his position, it was almost impossible to ignore them:

- Universality without the study of language diversity?

- Mentalism without psychology ("performance")?

- Logic/semantics without communication/discourse?

- Innateness without evolution?

- The centrality of acquisition without real child language data?

- Native speaker's intuition without spontaneous speech data?

- Ordered rules that mimicked diachrony, but Saussurean segregation? (Givón, On the Intellectual 6)

Givon's approach to the evolution of language can be described as "variationand-change and the functional-adaptive motivation". When discussing the origin and growth of language, he emphasises the necessity to dwell on diachronic principles, and holds that diachrony seems "to be unprecedented in biology, as against ontogeny and phylogeny. However, language diachrony turns out to recapitulate many of the general features of biological evolution" (Givón, On the Intellectual). The principles of Givon's biolinguistics may be summarised as follows:

- the biological variation within species/language on the genetic level as a major factor of the variation on the macro-level ("graduality of change");

- today's diversity in biological species and languages as determined by their earlier stages of evolution ("adaptive-selectional motivation");

- gradual variations on the gene level as responsible for a great divergence of characteristics among species and languages in comparison with their earlier evolutionary stages ("functional change and ambiguity before structural change and specialisation");

- the adaptation of living systems to the environment through the accommodation of their earlier functions ("terminal addition of new structures to older ones");

- the systemic acquisition of new functions in the process of evolution ("local causation but global consequences"); 
- universal processes as an evolutionary force for global changes in living systems and a determining factor for surface modularity ("unidirectionality of change").

As for the aspect of grammar in particular, according to Givón and his followers, paradigmatic rearrangements within grammatical categories are interpreted as encoding by language in the first place of those parts of the discourse that are of primary importance for interlocutors in the process of communication. Thus, systemic changes in grammar are registered earlier in the parts of grammatical paradigms that are more relevant for communication and more frequent in speech. For example, the paradigm of the first person is encoded in a specific way and shapes earlier in comparison with the 2nd and 3 rd in most languages; new case forms emerge primarily in the system of animate nouns; the word order evolves from SOV to SVO, etc. (cf.: Givón, Bio-Linguistics; Li)

To summarise everything stated above, it is possible to say that today's biolinguistics demonstrates approximately the same parity in the progress of giving answers to its five fundamental questions. The situation is very similar to the one described by Jenkins (35) at the beginning of the 21st century: much has been achieved in the study of the structure and acquisition of language, but less is known about physical mechanisms and evolution of language. However, the very emergence of biolinguistics has already proved that the profound move in ... disciplines towards re-integrating the sciences of life within a bio-evolutionary perspective is an open invitation to join the consortium. An intellectual framework is now in place whereby linguistics may take its rightful place along with its sister disciplines that study live organisms: biology, psychology and anthropology. With its integrative impulse, this research programme harkens all the way back to Aristotle, and thus closes an ancient circle (Givón, On the Intellectual).

\subsection{Autopoiesis as part of the holistic cognitive paradigm}

If modern science recognises the necessity of applying a complex anthropocentric analysis to all human activities, language included, some alternative systems of research data interpretations shall inevitably occur. Maturana and Varela's ideas of autopoiesis (the Santiago theory) and the Biology of Cognition have much in common with the principles of biolinguistics outlined above. Hence, this conception ought to be interpreted as an alternative system of cognition that allows embracing (to some degree) all the diversity and contradictoriness 
of the views on the empirical data accumulated in the course of scientific progress, though not explained on classical foundations.

As Maturana claims, since we exist in language, the domains of discourse that we generate become part of our domain of existence, and constitute part of the environment in which we conserve identity and adaptation (Maturana, Varela 234). Hence, cognition, or the process of learning (knowledge acquisition), is equal to the process of life, and is involved in the self-generation and self-perpetuation of living networks. In other words, cognition is the very process of life, while mental activity is a regulating evolutionary force for all living systems. Thus, any living system is a self-contained complex structure. It exists in constant interactions with the environment which impel certain changes within the system. In its turn, cognition generates the entire process of life - perception, emotions, and behaviour - and does not necessarily require a brain or nervous system.

Consequently, the constituent elements of such a system (which looks like a network) continually produce and transform one another in two ways: in a self-renewal mode, when a living organism builds and replaces its own structures, and as a generation of new structures - new connections in the autopoietic network. These changes are more evolutionary than cyclical. They take place as a result of environmental influences or the internal dynamics of the system itself. Thus, every living system has its reason regardless of the fact whether it possesses or does not possess its own nervous system and brain, and this assumption is an intrinsic characteristic of matter at all levels of life. To sum up, it is necessary to state that living systems are autonomous - the environment only "triggers off" some structural changes; but it does not specify or direct them. When a living system interacts with the environment, the environment influences its structural changes and determines the future behaviour of the system in general. Therefore, a structurally coupled system is a learning system. Consequently, continuing adaptation, learning, and development are the key characteristics of the behaviour of living systems in general. Moreover, all structural changes are kept in the memory of such a system, they determine the behaviour of the system, and make it impossible to influence the system directly as only it can "notice" which signals of the environment will be reflected by it, but which will be ignored (cf.: Maturana, Varela; Capra 35, 82-86).

Later, a Belgian physicist and chemist, Prigogine, modified the theory of autopoiesis, introducing the notion of the "dissipative structure" into it. He considered all living systems as open dissipative structures. Being far from 
equilibrium, these systems are nevertheless stable as the structural wholeness is maintained in spite of the ongoing flow and change of components. It is important to mention that the dynamics of dissipative structures specifically includes a spontaneous emergence of new forms of order: with the increase of the flow of energy, the system may encounter a point of instability known as a bifurcation point at which it can branch off into an entirely new state when new structures and new forms of order may emerge (cf.: Capra 86-89).

Regarding language evolution in the light of the Santiago theory, we may assume that language can be interpreted as an autopoietic structure of a specific order as its nature has some peculiarities that differentiate it from other living systems. On the one hand, language can hardly be separated from the human being, but at the same time, it possesses such a specific organisation that cannot be compared directly with the nervous system and brain, at least due to the fact that language representation is linear. Besides, the extent of language modularity - sound matter, the number and combinability of language signs and structures as means of nomination and communication - is originally limited by the physiological parameters of the organism and the capacity of the human brain to conceive and process information. In fact, they cannot expand infinitely. So, if language is viewed as an autopoietic system, the focus of research may lie in the domain of external "triggers", impelling the reconstruction of languages. Moreover, when applied to language, the Santiago theory (despite its "ultra-biological" orientation) conciliates such notions as "concept" and "meaning" when it "permits" language to deal with its own substance and modify itself within the sign system with its linear realisation and collective conventions in relation to meanings. These characteristics impose some limits on man's cognitive potentials as well: at present we cannot express ourselves but through language, though language is not needed directly for the process of thinking as such.

\subsection{Quantum Physics in language analysis}

Dwelling on alternative paradigms in language studies, we cannot but address theories of physics, since, at present, physics has established some links with linguistics and other anthropocentric sciences. Meanwhile, its role with regard to the theories interpreting the brain structure and the functions and work of the human mind is often considered as ambiguous. Two contradictory views on language and living matter can be represented as follows:

- laws of physics for inanimate matter are also valid for living matter; 
- laws of physics will have to be greatly modified if they are to account for the phenomena of life (cf.: Jenkins 39-40)'.

The deepest contradiction in views concerning the possibility of applying the laws of physics to language analysis lies in verifying objectivity and reliability of data interpretation, for in most cases, the only method to adopt or reject the results of experiments is introspection.

To start with, it is necessary to note that as regards the human mind and consciousness, quantum theories can be divided into two groups. The conceptions of the first group are based on the notion of "collective reason" - a unique quantum system similar to Jung's collective unconscious. This quantum system is sometimes represented as a separate phenomenon that is inherited genetically and contains all the knowledge accumulated by the mankind. The direction has much in common with esoteric studies, the notion of egregore, and exists as a branch of transpersonal psychology, the most famous representatives of which are Talbot, Kehoe, and Grof (Kornilov).

The second group deals with "quantum effects" that may help understand the workings of the human mind. The most famous representatives of this direction are Hameroff and Penrose. According to the theory of quantum effects, the human brain is described as a quantum computer with consciousness as its program interface, and soul as information accumulated on the quantum level. This information is indestructible: thus, when a person dies, the information of his/her life experience joins the universal quantum continuum and is stored there. Similar ideas are shared by a well-known Russian physicist, Mensky, who interprets the famous Everett approach to quantum mechanics:

(...) there is a representation in terms of a superposition, each element of which contains a definite observer state and a corresponding system state. Thus, with each succeeding observation (or interaction), the observer states 'branches' into a number of different states. Each branch represents a different outcome of the measurement and the corresponding eigenstate ${ }^{2}$ for the object-system state. All branches exist simultaneously in the superposition after any given sequence of observations. (Everett)

In other words, when we describe all possible configurations of a state for an unmeasured object from the macrocosm as a superposition expectancy (a superposition of the possibilities) of all these states, we consider that one of these states can get a determinate measurement record and become limited 


\section{ELENA TYURKAN}

to a single possibility. Hence, its expectancy will be described as position 1, all other states will get to the zero status, or zero measurement outcome. The challenge of the situation is to find out how the observer's choice, responsible for the object actualisation ${ }^{3}$, is made. So, classical quantum physics regards this choice as spontaneous. On the contrary, Mensky, developing Everett's idea, argues that the actualisation of one or another state depends on the observer's awareness of what world (branch) s/he is in at the present moment. Consequently, he insists on a volitional characteristic of every act on the part of the observer when $\mathrm{s} /$ he is deciding on one choice from all possible alternatives. According to Mensky, the choice of alternatives is predetermined by our existence as such: without it, we could not actualise in the quantum continuum for the very situation of non-actualisation is equal to the impossibility of life at all (cf.: Mensky 123, 192-210).

Quantum effects may lead us to rather an interesting interpretation of the "miracles" in our lives. Thus, miracles are described as probabilistic phenomena and stated to be possible only if the quantum continuum contains an alternative to such events (even a very improbable one). In other words, not every miracle may come true: as a very rough approximation, we can consider that a pauper has a chance to become a king, or someone who is seriously ill can recover, but a lame, one-eyed old man will never become Angelina Jolie.

In spite of numerous attacks on quantum theories when applied to human consciousness (very often, on the part of physicists themselves), even some critics admit that our volition really exists on the level of "quantum being" when we are involved in the processes of making decisions, in contrast to the neurophysiologists' claim that all our choices are an automatic program of the external influences of the world when a certain number of them come to a predetermined threshold (cf.: Kornylov). Thus, the most vexed problem, that arises naturally, lies in detecting the human brain areas responsible for quantum effects. Besides, a direct comparison of the human brain with the quantum computer sounds a bit inconsistent at present, because modern prototypical quantum computers can operate only at ultra low temperatures that are entirely incompatible with the existence of the human brain at all. Consequently, the ideas of quantum physics, applied to human consciousness, partly correlate with the Santiago theory and the idea of dissipative pertubation when the aspects of language variability and diversity are under analysis. As one's life is an infinite process of choosing between alternatives, let us assume as probable that there existed some ancient language faculty incorporated into the mind of 
our ancestors that could be developed under certain conditions. After people had settled on the territory of the Earth, they actualised themselves in different of Everett's quantum subworlds (branches), or their dissipative pertubation occurred in different focuses of the continuum reflecting the peculiarities of the territory and the way of living they led. These changes appeared to be influential for the work of the mind/brain. So, when a number of micro quantum effects overcame a certain threshold to trigger off changes of the macro world, the world image and its reflection by the mind structured extralinguistic reality in various modes that, in its turn, influenced the activation of the language faculty in a specific way. Hence, language as a semiotic and at the same time, autopoietic system of a specific order, rearranged and adjusted itself to the environment generating and providing a number of elements which made up a certain configuration on the surface level, or the level of expression. It is quite an important assumption, however, that any language retained some universal characteristics predetermined by our conditions for human habitation on the planet Earth: gravity, the existence of atmosphere, water sources, etc. Thus, it might be supposed that any language keeps its universal core, which is proved, for example, by Wierzbicka in her theory of primitives and natural semantic metalanguage (Wierzbicka). Consequently, the assumption of the existence of the universal core makes it possible to apply the rules of Generative Grammar to almost all languages (although it is necessary to note that the universal core, or language invariant, is rather a controversial issue for modern linguistics (cf: Evans \& Levinson)). Yet, as languages differ by their variable constituents on all levels of their structure, their variability and diversity, different typology included, can be interpreted as the evidence of their bearers' actualisation in different subworlds under the influence of dissipitave pertubation. Undoubtedly, these ideas may seem rather inconsistent without being underpinned by experimental data.

To summarise, it seems apparent that any approach within a holistic understanding of language requires a new methodological paradigm. Varela, one of the representatives of a relatively new direction in the science of consciousness - neurophenomenology - assumes that the work of consciousness must be studied as the analysis of an individual experience and the work of the neuron activity (Varela et al 26-27). Consequently, all bio-cognitive interpretations of data produced in experiments with the human mind may be regarded as a new epistemology for all anthropocentric sciences where linguistics and language are given a very significant role. As Maturana and Varela note: 
By existing, we generate cognitive "blind spots" that can be cleared only through generating new blind spots in other domains. We do not see what we do not see, and what we do not see does not exist... The business of living keeps no records concerning origins. All we can do is to generate explanations, through language, that reveal the mechanism of bringing forth a world. (Maturana \& Varela 242)

\section{Universal typology and its challenges}

Pursuing the subject of the origin of languages and their diversity, the issue of a universal core or metalanguage (etalon language) appears to be rather essential as one of the major goals for a holistic anthropocentric paradigm is to establish universal foundations of language typology. The idea to create an etalon language is not new: as Shulze notes, the methodical descriptive paradigm has oscillated between two poles - inductive and deductive procedures. In the medieval period it was embodied in the attempts to create universal grammars. The conception is based on the logical substrate uniformity and the explanatory access to language, and reflects the philosophical traditions of rationalism, especially its variant in terms of Wolffian logicism, sensualism, and empirism. Thus, language data were considered to be a material and habitus for the mind, though the peculiarities of a certain language were not taken into much consideration (cf.: Schulze). As Wierzbicka claims, a search for some universal logical laws providing an explanatory basis for the expression of thought through language data has something in common with the system of functional concepts in cognitive linguistics, but the difference is that the starting point of the analysis for cognitive research lies in the domain of a definite language paradigm. Therefore, only language data can give us the key to the universals of language typology (cf.: Wierzbicka 16).

Hence, one may conclude that to get an understanding of language evolution and functioning, modern scholars have to deal with the description of a routinised system of stimuli determining the emergence and presentation of a sign expression, or a "contextual explication of the sign" (Boldyrev 15). If language, according to Maturana and Varela, is a thing "we live in" (Maturana \& Varela), one may consider that, on the one hand, it ought to reveal some similarities and integrity, typical for all human beings, in the ways of presenting general encoding modes for the information that comes from extra-linguistic reality. On the other hand, language encoding ought to reflect 
some global changes which take place in the outer world, but may refer to a definite community. All in all, the processes of encoding are often connected with the language rearrangement on the global level: language develops and may show tendencies for a type change. Thereon, the theory of the language determinant introduced by a Russian scholar, Melnikov, in the 1960 can be of interest in terms of the holistic approach to language typology.

Being a cybernetician and a linguist, Melnikov proposed a hypothesis about the primacy of the communicative perspective and the geographical factor for language evolution. It should be noted that, in some way, the conception has something in common with Givón's and J. Nichols' theories (cf.: Givón, BioLinguistics; Nichols). According to Melnikov, language is not just an instrument of thinking, but in the first place a means of communication, possessing two determinants - internal and external. The internal determinant defines the mode of functioning for a peculiar language system, while the external one delimits those aspects that are responsible for generating parameters of the global world image within one and the same community. Moreover, external factors also determine in what nodes/points of the world image a language group experiences lack of cognitive data, how these required cognitive data are obtained through the processes of communication to make it successful, and what settings are exactly kept during such "adjustments". Accordingly, communicatively relevant language characteristics include the number of language bearers (large/small groups), homogeneity/heterogeneity of the group from the point of view of language content, and the mode of communication: the absence/presence of some time/space limits on intercommunication intervals, a sedentism/nomad way of living, etc. These differences in language groups result in the non-identity of the language communicative function and its variability.

One of the main aspects of the theory is the rearrangement of language systems towards the lexicalisation or grammaticalisation determinant. It is necessary to mention that the notions of lexicalisation and grammaticalisation are not new. In fact, they were introduced by de Saussure and Baudouin de Courtney, and have been studied by many prominent scholars (cf.: Brinton \& Traugott; Bybee et al; Hein; Heine et al; Himmelmann; Hopper and Traugott; Lehmann; Maysak; Nichols; Talmy; inter alia). As for the theory of Melnikov, grammaticalisation and lexicalisation are treated as a global systemic change accompanied by a certain number of tendencies. Thus, grammaticalisation is observed when verbal semantics is expressed prevalently in the roots; vowels are used mostly as grammatical categorial markers; consonants perform the 
function of elements responsible for building lexical meanings. Explicit tendencies of grammaticalisation can be traced in the group of Semitic languages. In its turn, lexicalisation is characterised by the tendency to express information with the help of simple lexical roots that makes it a typical feature of isolating languages (e.g.: the omission of the plural form, aspect distinctions, predicate-object agreement markers if there are other (lexical) indicators in the context, the coincidence of syllables, morphemes and words in their structure, a fixed word order in Chinese) (cf.: Melnikov, Sistemnaya Typologiya Yazykov: Sintez; Sistemnaya Typologiya Yazykov: Printsypy).

At present, it is universally acknowledged that most modern languages can hardly be classified as belonging to a single typological group. This phenomenon is quite explainable: language is a social dynamic system which develops with the society, interacts with other languages and cultures, and may lose or acquire some of its characteristics. Hence, original language features can vary under the influence of numerous factors lying beyond the boundaries of language. Thereby, the typological theory by Melnikov may help us understand and explain the reasons of changing the determinant. For example, the change of the determinant from grammaticalisation to lexicalisation, which has resulted in acquiring the features of an isolating typological group, took place in the case of the English language, originally inflectional At present, modern English demonstrates a number of characteristics typical for isolating languages, namely conversion, a fixed word order, a polyfunctional status of some elements, such as round, over, out, etc. Although it should be noted that all Germanic languages are influenced by this tendency, the system of the English language has undergone the most significant shifts.

Being a global typological factor, the change of the determinant affects the system of grammar as an organising and classifying constituent of language in the first place. Accordingly, a number of questions that arise naturally may include: Does the change of the determinant imply a drastic shift in the national world image and, as a consequence, the reconstruction of the national consciousness? Do these changes affect the processes of categorisation and conceptualisation? What factors - economic, social, political - trigger off the beginning of the process? Why is it that the change of the determinant does not affect all languages of the same group/type identically? Disappointingly, Melnikov did not give answers to these questions, and therefore, a valid theory of the determinant change is a matter to be studied in the future. It may turn out that the functional-cognitive paradigm and biocognitive theories are able 
to prompt some theoretical considerations and provide empirical data to explain explicitly global changes in the development of language.

Going back to quantum theories, some suggestions may be accessible on the path to the truth: since the world (and human beings as its immediate constituents) exists simultaneously in a multi-dimensional space (as time is an irrelevant notion for quantum physics), we, as language bearers, are represented simultaneously in the past, present, and future. Therefore, the current status of the English language as the global means of communication may have been anticipated by its change of the determinant and the language type long ago, on the ancient stage of its development (though, of course, it is necessary to admit that such assumptions need to be verified by interdisciplinary data, otherwise, they would risk to remain purely hypothetical).

\section{Some perspectives of studying Grammar}

As language development is connected with changes in grammar in the first place, studying grammar can be of utmost concern when following the "mentality" of the originated structures from the perspective of a diachronic and synchronic description. The fact is that grammar always presupposes some abstraction, but "even very abstract meanings may not become grammatical" (Plungyan 7, as translated by Elena Tyurkan). For example, the category of the article determination is expressed in the Russian language with the help of lexico-grammatical means; or vice versa, while it is grammatical in the system of the Russian verb, the category of reflexivity can be described as a "valency category" (Dolinina's term) in English, and refers to the level of semantic changes which occur within the environment of the verb.

Thus, the English structure $A$ girl went out of the house is translated into Russian as Из дома вышла девочка, but The girl went out of the house is equal to Девочка вышла из дома. The category of the article determination is rendered with the help of the word order and a theme-rheme rearrangement in Russian. Or the English sentence Is the pie tasty? can be rendered in Russian as Вкусный nupoz-mo? where the pie corresponds to the combination of the noun with a particle то.

To illustrate reflexivity, the Russian sentence Он умылся и оделся has the following presentation in English: He washed and dressed (himself) where himself can be rather easily omitted. While it is a morphological category in Russian, 


\section{ELENA TYURKAN}

reflexivity in English is a characteristic of semantic changes in the valency of the verb defined by a specific surface configuration due to its combinability with the subject and object. Changes within the subject-verb-object relations (SVO structure) lead to a different presentation and understanding of the situation denoted by the verb, but not to any morphological changes of its form: $\mathrm{He}$ washed (the floor) and dressed (his child) (compare with the corresponding Russian structure: Он помыл пол и одел ребенка).

So, if grammar gives some keys to the general understanding of language organisation and functioning, the focus of the research related to the holistic paradigm should lie in the study of the characteristics constituting grammar of a particular language. Such features are quite numerous. However, as for these aspects, theoretical assumptions and scholars' views differ considerably. The main controversial issues include:

- Should we search for one fundamental feature that clearly distinguishes the grammatical and the non-grammatical, or does this distinction rest on a number of features (at that, it is not necessary to require from an element, which is considered to take a grammatical function, the presence of the whole set of grammatical features simultaneously)?

- Is the opposition of the grammatical and the non-grammatical rather strict, or is it more reasonable to represent it as a gradual phenomenon, i.e., a prototypically organised category with a number of transient areas?

It is widely acknowledged that the differences between grammatical categories are crucial for language typology. Plungyan (13-15) compares grammar of a particular language to a certain questionnaire that reflects major peculiarities of the national world image and must be filled in correctly by every speaker if $\mathrm{s} /$ he wants to produce an appropriate utterance in this language. Moreover, mental operations underlying grammatical categories can give us keys to the work of consciousness in general and in particular: global changes in grammar could be connected with the "autopoietic" reconstruction of the language system under the external influence.

To summarise, one may state that as grammatical structure does not tend to develop as fast as lexis, every time changes in grammar influence radically the whole language. If we admit some external influence on language as on an autopoietic structure, it becomes possible to classify such influences as a bifurcation disturbance resulting in the modularity of the language interface (such as the loss of endings in English, the development of the category of 
aspect in Russian, etc). Hence, the focus of the research in this field may lie in the sphere of human-language intentions (or "intention stance" according to Dennett) determined by a broad range of economic, social, political factors, and can be introduced as an analysis of external stimuli which ought to be identified as crucial for a radical reorganisation of the language structure. Moreover, not all stimuli may be "powerful" enough to change systemic "settings". That is why further elucidation of the degree of prominence that can be ascribed to each stimulus is required.

Thus, when studying grammar on the basis of the holistic approach, it may become possible to answer some important questions concerning the diversity of grammar structures. The first one is connected with the degree of importance of grammatical paradigms for various languages. In other words - what grammatical paradigms can be considered a constituent of an absolute grammatical core, or a universal grammar set (Plungyan's term) that functions as an organising centre or nucleus for any language. For example, the systems of tense, aspect, number, voice, mood are regarded as categories that define the structure and most essential features of a language. Besides, it is important to follow the evolution of each universal core category, and trace the extent of this evolution. The next issue concerns a study of the cognitive basis which lies beyond the general meaning of grammatical categories, and what makes up the invariant of each of them. Accordingly, other issues can be referred to as principles of comparative description for grammatical semantics providing the key to understanding human consciousness operations, the interconnection of lexical and grammatical meanings in the processes of evolution as the reflection of the world image formation, the variability of grammatical categories within their own structure when a category reveals the 'defective forms' that "violate" its paradigm.

With regard to the cases of the paradigmatic violations, some observations ought to be made. For example, a number of Russian and English qualitative adjectives мертвый/dead, конечный/final, лысый/bald, больной/sick, etc., can hardly be used with degrees of comparison (though sometimes, decomposed units based on their use as part of set expressions are found in both languages, such as - мертвее не бывает/deader than a door nail). Other examples concern the absence of forms in the system of case, aspect, number (some Russian verbs do not have future forms, such as the verb победить (to win); similarly, English modal verbs possess a defective paradigm, as well as the group of pluralia tantum and singularia tantum nouns, etc. One more phenomenon referring to the cases of paradigmatic "violations" is classified as a systemic/random 
(stochastic) homonymy ("coincident positions" according to Plungyan), namely the coincidence of all endings in the system of the Russian adjectives in plural, the homonymy of some case forms (genitive, dative, locative) in the system of the Russian nouns of the 3 rd, etc. Such "defects" are rather typical for almost any natural languages and can be also referred to the language economy principle mentioned above. Moreover, these deviations contribute to the overall picture of the holistic linguistic world image and help understand the relation between our consciousness and the outer world.

\section{Conclusion}

One may say that modern linguistics requires research to be cross-disciplined, multi-sided, and typologically oriented. At present, a systemic approach, developed in the works of structuralists, is given a new incentive because "to clarify all facts under analysis we have to establish links between historical, geographical, physiological, psychological, and even physical and mechanical matters" (Baudouin de Courtney 63, as translated by Elena Tyurkan). A comprehensive approach to the description of language phenomena on functional-cognitive foundations allows to combination of classical views with a multi-aspectual interdisciplinary analysis as the key to the functioning of the human psyche.

At the same time, subjectivity, which science has been constantly trying to avoid, is nothing, but an inevitable consequence of our attempts to penetrate into the inner-depths of the human mind. But today's subjectivity implies dealing with large corpora of knowledge processed by scholars, and a fundamental integral comparative basis of research.

Consequently, a comprehensive holistic linguistic analysis must meet the demands of

- being synergetic, regarding language as a versatile phenomenon that should be studied by different sciences;

- using large corpora of language data;

- being language type-specific;

- regarding diachronic data as information of great value for a synchronic explanatory paradigm;

- recognising introspection as a full-fledged element of research. 
Following these principles, it seems possible to get access to universal knowledge, a part of which we appear to be.

\section{Notes}

1. Jenkins gives a review of the theories of Quantum Physics in their validity to be applied to biological issues, language included, in: Jenkins 20-26; 32-35; 41-45.

2. The word eigenstate originates from the German or Dutch word eigen and means inherent or characteristic. An eigenstate is defined as the measured state of some object possessing quantifiable characteristics such as position, momentum, etc.

3. Actualisation refers here to a limited to one possibility state of an object.

\section{Works Cited and Consulted}

Bickerton, Derek. Language and Species. Chicago \& London: The University of Chicago Press, 1990. Print.

Brinton, Laurel J. \& Elizabeth C. Traugott. Lexicalization and Language Change. Cambridge: Cambridge University Press, 2005. Print.

Bybee, Joan et al. The Evolution of Grammar: Tense, Aspect and Modality in the Languages of the World. Chicago: University of Chicago Press, 1994. Print. Boldyrev, Nokolay N. Kategorialnoye Znacheniye Glagola: Sistemniy i Funktsionalniy Aspect. St. Petersburg: RGPU im. A.I. Gertsena, 1994. Print.

Baudouin de Courtney, Ivan A. O Smeshannom Haraktere Vseh Yazikov. Izbrannie Trudy po Obshchemu Yazikoznaniyu. Vol.1. Moscow: Nauka, 1963. Print.

Capra, Fritjof. The Hidden Connections: A Science for Sustainable Living. London: Harper Collins, 2002. Print.

Chomsky, Nicholas. Language and Politics. Montreal: Black Rose, 1983. Print.

---. Language and Problems of Knowledge. The Managua Lectures. Cambridge, MA: MIT Press, 1988. Print.

--.. "Linguistics and Cognitive Science: Problems and Mysteries". Ed. Asa Kasher. The Chomskian Turn: Generative Linguistics, Philosophy, Mathematics, and Psychology. Oxford: Blackwell, 1991. 26-53. Print.

---. New Horizons in the Study of Language and Mind. Cambridge: Cambridge University Press, 2000. Print.

Croft, William. "Some Contributions of Typology to Cognitive Linguistics and Vice Versa." Ed. Theo Janssen and Gisela Redeker. Cognitive Linguistics: Foundations, Scope, and Methodology. Berlin, N.Y., 1999. 61-93. Print. 


\section{ELENA TYURKAN}

Dennett, Daniel. Kinds of Minds: Towards an Understanding of Consciousness. New York: Basic Books, 1997. Print.

Devitt, Michael \& Kim Sterelny. "Meaning and Naming." Language and Reality. MIT Press, 1999. Web. 25 December 2013.

Dirven, René \& Marjolijn Verspoor. Cognitive Exploration of Language and Linguistics. Amsterdam: John Benjamins Publishing Company, 2004.

Dolinina, Inga B. Semanticheski Znachimyje Kategorii Angliyskogo Glagola. Leningrad: Nauka, 1989. Print.

Evans, Nicholas \& Steven C. Levinson. "The Myth of Language Universals: Language Diversity and Its Importance for Cognitive Science." Behavioral and Brain Sciences, 32(5), 2009. Web. 429-492. 14 January 2014.

Everett III, Hue. "'Relative State' Formulation of Quantum Mechanics". Reviews of Modern Physics. Vol. 29. No. 3. 1957. Web. 28 February 2014.

Fauconnier, Gilles. "Cognitive Linguistics." Encyclopedia of Cognitive Science. n.d. Web. 25 February 2014.

Fauconnier, Gilles \& Mark Turner. The Way We Think: Conceptual Blending and the Mind's Hidden Complexities. New York: Basic Books, 2002. Print.

Fedin, Sergey. "Legko li Vyuchit Sotnyu Yazykov?” Nauka I Zhizn. (4). 1999. Web. 27 February 2014.

Fodor, Jerry A. Modularity of Mind: An Essay on Faculty Psychology. Cambridge, MA.: MIT Press, 1983. Print.

Frumkina, Revekka et al. Ed. Yuliy A. Shreyder. Semantica i Kategorizatsiya. Moscow: Russian Dictionaries. 1991. Print.

Givón, Talmy. Bio-Linguistics: The Santa Barbara Lectures. Amsterdam: John Benjamins, 2002. Print.

---. On the Intellectual Roots of Functionalism in Linguistics. University of Oregon. n.d. Web. 25 February 2014.

---. "The Visual Information-processing System as an Evolutionary Precursor of Human Language." The Evolution of Language Out of Pre-language. Ed. Talmy Givón et al. Amsterdam, Philadelphia: John Benjamins, 2002. 35o. Print.

Hopper, Peter J. \& Elizabeth C. Traugott. Regularity in Semantic Change. Cambridge: Cambridge University Press, 2003. Print.

Jenkins, Lyle. Biolinguistics: Exploring the Biology of Language. Cambridge, MA.: Cambridge University Press, 2000. Print.

Golestani, Narly et al. "Brain Structure Predicts the Learning of Foreign Speech Sounds." Cerebral Cortex. BBC. 26 November 2012. Web. 25 February 2014. 
Greenberg, Joseph H. et al. "Memorandum Concerning Language Universals." Universals of Language. Ed. Joseph Greenberg. Cambridge: The M.I.T. Press, 1963. 255-264. Print.

Heine, Bernd. "Grammaticalization Chains." Studies in Language. 1992. 16.2. (1992): 335-368. Print.

Heine, Bernd et al. Grammaticalization: a Conceptual Framework. Chicago: University of Chicago Press, 1991. Print.

Himmelmann, Nicholas. What Makes Grammaticalization - a Look From Its Components and Its Fringes. Berlin: Mouton de Gruyter, 2004.

Hopper, Peter 7. On Some Principles of Grammaticalization. Ed. Elizabeth C. Traugott \& Bernd Heine. Amsterdam: John Benjamins, 1991. Vol. 1. Print.

Ikegami, Takashi \& Jordan Zlatev. "From Pre-representational Cognition to Language." Body, Language and Mind. Vol 1: Embodiment. Ed. Tom Ziemke et al. Berlin: Mouton, 2007. Web. 241-283. 23 January 2014.

Kibrik, Alexander Y. "Sovremennaya Lingvistika: Otkuda i Kuda?" Vestnik Moskovskogo Universiteta. Ser. 9. Moscow: Filologiya, 1995. 93-103. Print.

Kibrik, Alexander Y. \& Vladimir A. Plungyan. "Funktsionalizm." Sovremennaya Amerikanskaya Lingvistika: Fundamentalnyje Napravleniya. Moscow: URSS, 2002. 276-339. Print.

Kornilov, Vyacheslav A. "Kritika Kvantovyh Teorij Soznaniya." Samizdat. 23 February 2014 <http://samlib.ru/k/kornilow_w_a/kritika_quantovyh_ teorij_soznanija.shtml>

Kravchenko, Alexander V. "Kognitivnaya Lingvistika i Novaya Epistemologiya." Izv. RAN. Seriya literatury i yazyka. Vol. 6o. no. 5. M., 2001. 3-13. Print.

--.. "Toward a Bio-cognitive Philosophy of Language." Perspectives: Fournal for Interdisciplinary Work in the Humanities. 1.4. academia.edu, 2002. Web. 25 February 2014.

---. Sign, Meaning, Knowledge. An Essay in the Cognitive Philosophy of Language. Frankfurt/Main: Peter Lang, 2003. Print.

--.. "Kognitivnaya Lingvistika Segodnya: Integratsionnje Protsessy i Problema Metoda." Voprosy Kognitionoy Lingvistiki, No. 1. 2004. 37-52. Print.

--.. Kognitionyj Gorizont Yazykoznaniya. Irkutsk: Izdatelstvo BGUEP, 2008. Print.

Kubryakova, Yelena. S. "Evolutsiya Lingvisticheskih Idei vo Vtoroy Polovine XX Veka (Opyt Paradigmalnogo Analiza)." Yazyk Nauki Kontsa XX Veka. Moscow: Russian State University for the Humanities, 1995 144-238. Print. 


\section{ELENA TYURKAN}

Lakoff, George. "Categories: An Essay in Cognitive Linguistics." Linguistics in the Morning Calm. Seol: Hanstein, 1983. 139-193. Print.

---. "Linguistics and Natural Logic". Synthese, 1970 (22). 151-271. Print.

Lakoff, George \& Mark Johnson. Philosophy in the Flesh: The Embodied Mind and Its Challenge to Western Thought. New York: Basic Books, 1999. Print.

Langacker, Ronald. Foundations of Cognitive Grammar. Vol. 1. Stanford: Stanford University Press, 1987. Print.

Larina, Mariya B. "K Voprosu o Sposobah Strukturirovaniya Znacheniya v Yazyke: Kontsept, Znacheniye, Ponyatiye, Obraz." Vestnik Kuzbasskoy Pedagogicheskoy Akademii. (1-2). 2010. Web. 15 January 2014.

Lehmann, Christian. Thoughts on Grammaticalization: a Programmatic Sketch. 2nd ed.: Erfurt: Seminar fur Sprachwissenschaft der Universitat, 2002. Print.

Li, Charles N. Mechanism of Syntactic Change. Austin: University of Texas Press, 1977. Print.

Maturana, Humberto \& FranciscoVarela The Tree of Knowledge: The Biological Roots of Human Understanding. Boston, MA: Shambala, 1988. Print.

Maysak, Timur A. Tipologiya Grammatikalizatsii Konstruktsiy s Glagolami Dvizhenija i Glagolamy Pozitsii. Moscow: Languages of Slavic Culture, 2005. Print.

McCawley, James D. "The Role of Semantics in a Grammar." Universals in Linguistic Theory. New York: Holt, Rinehart and Winston, 1968. 125-169. Print.

Melnikov, Gennady P. Sistemnaya Typologiya Yazykov: Printsypy, Metody, Modeli. Moscow: Nauka, 2003. Print.

---. Sistemnaya Typologiya Yazykov: Sintez Morfologicheskoy Klassifikatsii Yazykov so Stadialnoy: Kurs Lektsiy. Moscow: Izd-vo RUDN, 2000. Print.

Mensky, Mikhail B. Chelovek $i$ Kvantoryj Mir: Strannosti Kvantovogo Mira i Tayna Soznanija. Fryazino: Vek-2, 2005. Print.

Miller, George \& Philip Johnson-Laird. Language and Perception. Cambridge, MA: Cambridge University Press, 1976. Print.

Nichols, Johanna. Linguistic Diversity in Space and Time. Chicago: University of Chicago Press, 1992. Print.

Pinker, Steven. The Language Instinct: How the Mind Creates Language. New York: Harper Perennial, 1995. Print.

Plungyan, Vladimir A. Vvedenije v Grammaticheskuju Semantiku: Grammaticheskije Znachenija i Grammaticheskije Sistemy razykov. Moscow: Rossiysky gosudarstvenny gumanitarny universitet, 2011. Print. 
Rakhilina, Ekaterina V. 30 let Spustya: Novyje Metody, Instrumenty $i$ Zadachi Kognitionoy Lingoistiki. n.p. n.d. Web. 28 February 2014.

Tomasello, Michael M. \& Joseph Call. Primate Cognition. Oxford: Oxford University Press, 1997. Print.

Schulze, Wolfgang. The Architecture of a 'Grammar of Scenes and Scenarios'. 1999. Web. 25 February 2005.

Talmy, Leonard. "Lexicalization Patterns: Semantic Structure in Lexical Forms." Language Typology and Syntactic Description. Vol. 3: Grammatical Categories and the Lexicon. Ed. Timothy Shopen. Cambridge: Cambridge University Press, 1985 · 57-149. Print.

Taylor, John R. Linguistic Categorization. Prototypes in Linguistic Theory. Oxford: Clarendon, 1989. Print.

Thompson, Sandra A. "On Addressing Functional Explanation in Linguistics." Language and Communication. 11. (1991): 93-96. Print.

Varela, Francisco et al. The Embodied Mind: Cognitive Science and Human Experience. Cambridge: MIT Press, 1991. Print.

Wiezbicka, Anna. Semantics: Primitives and Universals. Oxford; New York: Oxford University Press, 1996. Print.

Zaliznyak, Anna A. Mnogoznachnost v razyke i Sposoby Eyo Predstavleniya. Moscow: Yazyki slavyanskih kultur, 2006. Print.

Zlatev, Jordan. "A Hierarchy of Meaning Systems Based on Value." Proceedings of the First International Workshop on Epigenetic Robotics. Lund University Cognitive Science 85. Ed. Christian Balkenius et al. 2001. Web. ${ }_{5}$ February 2014 .

--. "Mimesis: the "Missing Link" Between Signals and Symbols in Phylogeny and Ontogeny?" Journal of Physiology. 2008. 137-152. Web. 30 January 2014 .

ELENA TYURKAN (BELICHENKO) graduated from the faculty of History and English of the Murmansk State Teacher Training Institute in 1991. In 1996, she took a postgraduate course at the Herzen State Pedagogical University of Russia where she defended, in 2000, the thesis "Functionalgrammatical Variation of the Lexemes Denoting Parts of the Human Body (with special reference to 'noun-verb' pairs, namely 'hand - to hand', 'head - to head', 'leg - to leg', 'shoulder - to shoulder')". At present, she works as an Associate Professor at the Chair of Modern Languages of the Murmansk State 
Humanities University. Her research interests include functional linguistics, cognitive typology, and comparative linguistics. Among the courses she teaches are Theoretical Grammar, Cognitive Linguistics, Functional Linguistics, and Comparative Linguistics.

elenabelichenko@mail.ru 